Cite this: J. Mater. Chem. C, 2014, 2, 2707

Received 25th November 2013 Accepted 28th January 2014

DOI: $10.1039 / c 3 t c 32317 j$

www.rsc.org/MaterialsC

\section{Au-Pt alloy nanocatalysts for electro-oxidation of methanol and their application for fast-response non-enzymatic alcohol sensingt}

\author{
Liyan Zhao, Joseph P. Thomas, Nina F. Heinig, Marwa Abd-Ellah, Xiongyao Wang \\ and K. T. Leung*
}

Electrodeposited Au-Pt alloy nanoparticles supported on ITO-glass substrates have been used as a model catalyst to study the electro-oxidation of methanol $(0.5 \mathrm{M})$ in a $\mathrm{KOH}(0.5 \mathrm{M})$ electrolyte. Using cyclic voltammetry, we show that the Au-Pt alloy nanoparticles exhibit a significantly higher catalytic activity than the Pt nanoparticles, while the Au nanoparticles show no catalytic affinity toward electro-oxidation of methanol. The Au-Pt alloy nanoparticles are also found to be catalytically more reactive than bimetallic Au-core Pt-shell and Pt-core Au-shell nanoparticles. We further show that these Au-Pt alloy nanoparticles working in alkaline solution could act as an amperometric sensor for the determination of alcohol concentration. The exceptional performance of this nanoalloy sensor, including its short response time $(2 \mathrm{~s})$, relatively large linear range $(1-11 \mathrm{mM})$, low detection limit $(0.1 \mathrm{mM})$, high sensitivity $\left(0.043 \mathrm{~mA} \mathrm{~cm}^{-2} \mathrm{mM}^{-1}\right.$ ) and long-term stability (over 90 days), are also characterized. The present nanoalloy sensor also has the lowest working potential $(0.25 \mathrm{~V})$, making it less prone to an interference effect.

\section{Introduction}

The study of methanol electro-oxidation has attracted a lot of attention due to its broad applications in fuel cells., ${ }^{\mathbf{1} 2}$ Platinum nanoparticles (NPs) have been traditionally used as an effective catalyst, ${ }^{3,4}$ and it is well established that electro-oxidation of methanol on a Pt surface follows a dual-path mechanism. ${ }^{5}$ In particular, methanol can be oxidized directly to $\mathrm{CO}_{2}$ through a reactive intermediate, or indirectly first to $\mathrm{CO}$ at a relatively low potential and then to $\mathrm{CO}_{2}$ only at a higher potential. The earlier work has shown that in addition to CO, formic acid and formaldehyde could act as intermediates during electro-oxidation of methanol. ${ }^{6}$ One important challenge is the poisoning of $\mathrm{Pt}$ catalysts by adsorbed CO-like species. ${ }^{7}$ As Au NPs have been reported to be extraordinary catalysts for CO oxidation, ${ }^{\mathbf{8 , 9}}$ which is part of the indirect reaction pathway, this affinity for CO oxidation has created a strong interest in $\mathrm{Au}-\mathrm{M}$ bimetallic or alloy NPs (where $\mathrm{M}$ is, e.g., $\mathrm{Pt},{ }^{10-12} \mathrm{Pd},{ }^{13} \mathrm{Rh},{ }^{14}$ and $\mathrm{Cu}^{15}$ ) for methanol electro-oxidation. In fuel cell application, carbon black is often used as a support for the noble metal electrode. However, the chemisorption of surface oxygen complexes on the high surface area of this type of support could complicate the study of these catalysts, particularly in probing the mechanism

WATLab and Department of Chemistry, University of Waterloo, Waterloo, Ontario, Canada N2L 3G1.E-mail: tong@uwaterloo.ca

$\uparrow$ Electronic supplementary information (ESI) available. See DOI: $10.1039 / \mathrm{c} 3 \mathrm{tc} 32317 \mathrm{j}$ of electro-oxidation of methanol at the active sites of the noble metal. In this work, we investigate the methanol electro-oxidation in alkaline medium using $\mathrm{Au}, \mathrm{Pt}$ and Au-Pt NPs as model catalysts electrodeposited onto ITO-glass substrates (as the support). Such systems offer relatively simple model systems to investigate mechanistically the surface chemistry involved because the ITO-glass support has been found to have no effect on methanol electro-oxidation. We also demonstrate the superior catalytic performance of Au-Pt alloy NPs compared to those of bimetallic Au on Pt and Pt on Au NPs. It is well known that methanol electro-oxidation could occur in acidic $\left(\mathrm{H}_{2} \mathrm{SO}_{4}\right)$ medium. We focus our present study on alkaline medium $(\mathrm{KOH})$ because fuel cell performance has been found to be significantly better in alkaline medium. ${ }^{\mathbf{1 6 - 1 8}}$

Monitoring alcohol concentration in a solution with a high sensitivity and a short response time is important in many industries. Electrochemical alcohol sensing is one of the most promising methods due to its simplicity and accuracy. Two types of sensors based on their electrode materials have been widely studied. The enzyme-modified electrode employs either alcohol oxidase $\mathrm{e}^{\mathbf{1 9 2 0}}$ or alcohol dehydrogenase,,$^{\mathbf{2 1 , 2 2}}$ and it is known to be not only expensive but also bio-inactive at room temperature. A non-enzymatic sensor is based on a metal or metal oxide electrode, and there are a number of such electrochemical sensors, all with their advantages and challenges. For example, an $\mathrm{Au}$ electrode modified by co-electrodeposited Pt and $\mathrm{WO}_{3}$ (ref. 23) has a long response time and a short lifetime due to the long-term dissolution of $\mathrm{WO}_{3}$. Such a sensor, 
however, has a very high sensitivity, and its reproducibility and accuracy of electrochemical sensing are comparable to traditional methods such as the near-infrared methods. ${ }^{24} \mathrm{~A} \mathrm{RuO}_{2}$ modified Ni electrode ${ }^{25}$ and a Ni/Pt/Ti nanostructured thin film sputtered on an $\mathrm{Al}_{2} \mathrm{O}_{3}$ substrate ${ }^{26}$ also exhibit a relatively long response time. A CuO-modified copper disc electrode has shown a very poor detection limit, despite its good reproducibility. ${ }^{27} \mathrm{~A}$ Ni-Pt alloy film electrodeposited on an $\mathrm{Au} / \mathrm{Al}_{2} \mathrm{O}_{3}$ electrode can work as a sensor with a long stability of over 63 days, but it has a poor detection limit. ${ }^{28}$ For alcohol sensors based on an electrodeposited Ni-B thin film ${ }^{29}$ and on PtRuNi ternary alloy NPs electrodeposited on a glassy carbon electrode pre-coated with a multi-walled carbon nanotubes-ionic liquid gel film, ${ }^{30}$ their common disadvantage is the requirement to operate at a high over-potential, as is also needed for all of the aforementioned sensors (0.4-0.65 V). A high over-potential has been found to lead to interference effect and is therefore less desirable in sensor application. While a Pt electrode electrodeposited with a mixed oxide film of Co-Ni could work at a lower potential $(0.27 \mathrm{~V})$, it suffers from an extremely short lifetime of just 3 days. ${ }^{31}$

It is well known that Pt is a widely used electro-catalyst for electro-oxidation of alcohol. Here, by introducing $\mathrm{Au}$ into Pt in a simple, one-step co-electrodeposition method, we produce $\mathrm{Au}$-Pt alloy NPs on an ITO-glass substrate and demonstrate its superior performance as an alcohol sensor. Linear sweep voltammetry and chronoamperometry are used to characterize the electrochemical behavior of $\mathrm{Au}-\mathrm{Pt}$ alloy NPs and their catalytic activity in the electro-oxidation of alcohol.

\section{Experimental details}

Electrodeposition of Pt NPs, Au NPs, and Au-Pt alloy NPs were performed in a three-electrode cell with a potentio/galvanostat electrochemical workstation ( $\mathrm{CH}$ Instruments 660A). An ITOglass chip $\left(5 \times 15 \mathrm{~mm}^{2}, 0.7 \mathrm{~mm}\right.$ thick, with a sheet resistivity of 4-8 $\Omega$ per square) was used as the working electrode, along with a standard $\mathrm{Ag} / \mathrm{AgCl}$ reference electrode and a Pt-wire counter electrode. Three deoxygenated aqueous solutions of $1 \mathrm{mM}$ $\mathrm{PtCl}_{4}, 1 \mathrm{mM} \mathrm{AuCl}$, and $1 \mathrm{mM} \mathrm{AuCl}$, plus $1 \mathrm{mM} \mathrm{PtCl}_{4}$, each along with $0.1 \mathrm{M} \mathrm{NaClO}_{4}$ used as the supporting electrolyte, were used to prepare Pt NPs, Au NPs, and Au-Pt alloy NPs, respectively. The respective NPs were deposited onto ITO-glass substrates by amperometry at a constant potential of $-0.3 \mathrm{~V}(v s$. $\mathrm{Ag} / \mathrm{AgCl}, 3 \mathrm{M} \mathrm{KCl}$ ) for a selected amount of time. After the deposition, the sample was thoroughly rinsed with filtered deionized water (with a resistivity of $18.2 \mathrm{M} \Omega \mathrm{cm}$ ) and dried under $\mathrm{N}_{2}$ before further analysis. The surface morphology and crystal structures of the resulting electrodeposits were characterized by field-emission scanning electron microscopy (SEM) using a LEO FESEM 1530 microscope and glancing-incidence X-ray diffraction (GIXRD) using a PANalytical X'pert Pro MRD diffractometer, respectively. The corresponding chemical-state composition was analyzed by X-ray photoelectron spectroscopy (XPS) using a Thermo-VG Scientific ESCALab 250 Microprobe equipped with a monochromatic Al K $\alpha$ X-ray source $(1486.6 \mathrm{eV})$. High resolution transmission electron microscopy (HRTEM), using a Zeiss Libra $200 \mathrm{MC}$ microscope, has been used to investigate the structure of the AuPt alloy NPs, which were removed from the ITO-glass substrate by carefully scratching the surface. UV-Visible spectra of NPs on ITO-glass substrates were collected using a Lambda 1050 UV/VIS/NIR spectrometer equipped with an integrating sphere accessory.

The as-electrodeposited Pt NPs, Au NPs, and Au-Pt alloy NPs on ITO-glass substrates were used as the working electrodes in the subsequent electro-oxidation studies conducted with the same electrochemical workstation. We employed cyclic voltammetry to detect the oxidation features of these samples in a deoxygenated solution of $0.5 \mathrm{M} \mathrm{KOH}$ with and without $0.5 \mathrm{M}$ methanol. The potential was cycled between $-0.8 \mathrm{~V}$ and $1.0 \mathrm{~V}$ (vs. $\mathrm{Ag} / \mathrm{AgCl}$ ) with a scan rate of $10 \mathrm{mV} \mathrm{s}^{-1}$. For the alcohol sensing experiments, we employed the Au-Pt alloy NP working electrode and also conducted linear sweep voltammetry between 0 and $0.6 \mathrm{~V}$ at the same scan rate $\left(10 \mathrm{mV} \mathrm{s}^{-1}\right)$ in a deoxygenated solution of $0.5 \mathrm{M} \mathrm{KOH}$ and $6 \mathrm{mM}$ ethanol. After selecting the appropriate applied potential, amperometric measurement was performed in a $0.5 \mathrm{M} \mathrm{KOH}$ electrolyte at $0.25 \mathrm{~V}$ ( $v s \mathrm{Ag} / \mathrm{AgCl}$ ), with constant stirring in order to ensure transport of the analyte to the surface of the working electrode. Once the background current became stabilized, a desired amount of alcohol was injected into the solution and the amperometric response current was recorded.

\section{Results and discussion}

Fig. 1a shows that spherical Pt NPs were obtained by a $1 \mathrm{~s}$ electrodeposition. These NPs are well dispersed on the ITOsubstrate and they exhibit a narrow size distribution with an average size of $4 \mathrm{~nm}$ (Fig. 1b). A few sparsely distributed clusters of Pt NPs with an average cluster size of $25 \mathrm{~nm}$ are also observed. The XPS spectrum of the Pt $4 \mathrm{f}$ region (Fig. 1c) reveals the characteristic Pt $4 \mathrm{f}_{7 / 2}\left(\mathrm{Pt}_{4 \mathrm{f}}\right)$ peak at $71.3 \mathrm{eV}(74.7 \mathrm{eV})$ for metallic Pt. ${ }^{32}$ The weak feature near $78.5 \mathrm{eV}$ corresponds to In $4 \mathrm{p}$ of the ITO-glass substrate. For the $1 \mathrm{~s}$ Au electrodeposition, very uniformly dispersed spherical NPs (Fig. 1d) with a broader size distribution and a larger average size of $18 \mathrm{~nm}$ are obtained (Fig. 1e). The corresponding Au 4 f spectrum (Fig. 1f) shows the characteristic $\mathrm{Au} 4 \mathrm{f}_{7 / 2}\left(\mathrm{Au} 4 \mathrm{f}_{5 / 2}\right)$ peak at $84.0 \mathrm{eV}(87.7 \mathrm{eV})$ for metallic Au. ${ }^{32}$ For the $1 \mathrm{~s}$ electrodeposition carried out in the electrolyte containing both $\mathrm{PtCl}_{4}$ and $\mathrm{AuCl}_{3}$, the morphology of the electrodeposited NPs and their size distribution shown in Fig. $1 \mathrm{~g}$ and $\mathrm{h}$, respectively, reveal two groups of spherical NPs, one with an average size of $6 \mathrm{~nm}$ and the other with an average size of $40 \mathrm{~nm}$. When the electrolyte contains $\mathrm{PtCl}_{4}$ (Fig. 1a and $\mathrm{g})$, electrodeposition appears to follow a progressive growth mode. The Pt $4 f_{7 / 2}\left(P t 4 f_{5 / 2}\right)$ feature at $70.8 \mathrm{eV}(74.1 \mathrm{eV})$ for these NPs (Fig. 1i) is found to be $0.5 \mathrm{eV}$ lower than that for metallic Pt and can be assigned to the Au-Pt alloy. The formation of alloy is also consistent with the $\mathrm{Au} 4 \mathrm{f}_{7 / 2}\left(\mathrm{Au} 4 \mathrm{f}_{5 / 2}\right)$ feature at $83.9 \mathrm{eV}$ $(87.6 \mathrm{eV})$, which is $0.1 \mathrm{eV}$ lower than that for metallic Au. The lower binding energies found for both $\mathrm{Au} 4 \mathrm{f}_{7 / 2}$ and $\mathrm{Pt} 4 \mathrm{f}_{7 / 2}$ features of the $\mathrm{Au}-\mathrm{Pt}$ alloy NPs, relative to the respective metallic $\mathrm{Au}$ and Pt features, are in good agreement with the earlier reports, ${ }^{33-36}$ which is also supported by theoretical 

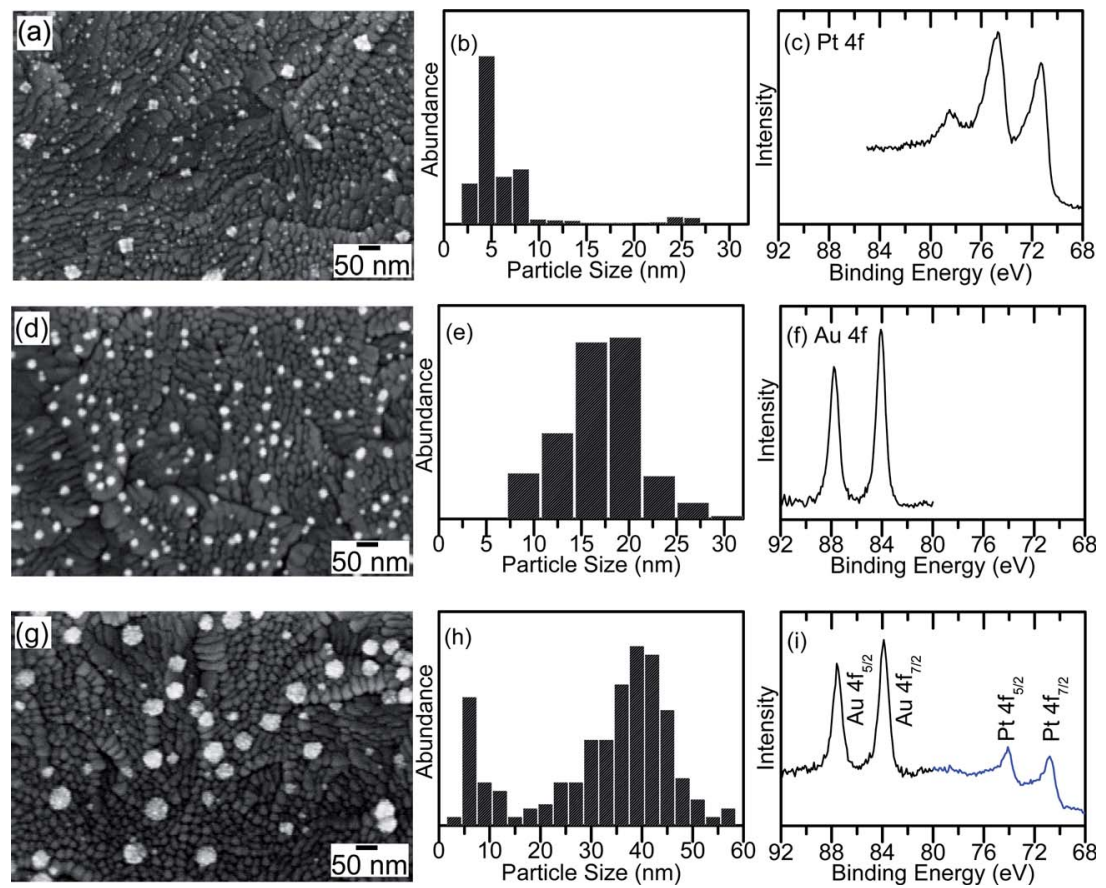

Fig. 1 SEM images (left column), particle size distributions (center column), and XPS spectra (right column) of the Au $4 \mathrm{f}$ and/or Pt $4 \mathrm{f}$ regions for $(a-c)$ Pt NPs, (d-f) Au NPs, and ( $g-i) A u-P t$ alloy NPs, all supported on ITO-glass substrates.

calculation using the local density functional method within the initial state approximation. ${ }^{33}$ From the atomic ratio of Au to Pt (2.59) estimated from the XPS peak intensities corrected by the respective relative atomic sensitivity factors, we deduce the alloy composition to be $\mathrm{Au}_{72} \mathrm{Pt}_{28}$. By increasing the deposition time to $5 \mathrm{~s}$, a nanocrystalline $\mathrm{Au}-\mathrm{Pt}$ alloy film is obtained and XPS analysis reveals the alloy composition to be $\mathrm{Au}_{71} \mathrm{Pt}_{29}$ (ESI, Fig. S1†). The longer deposition has resulted in an increase in the metal loading, which is shown to be a better sensor as discussed below.

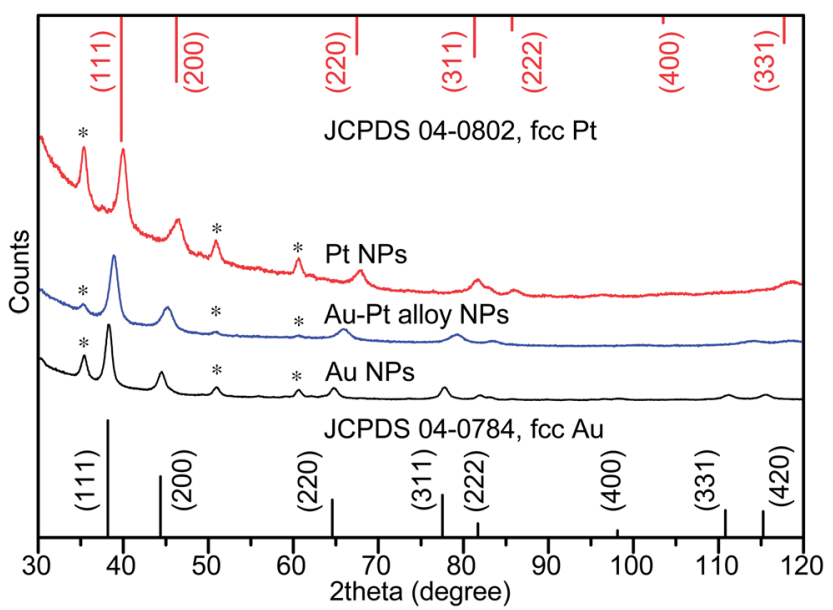

Fig. 2 GIXRD patterns of Pt NPs, Au NPs and Au-Pt alloy NPs on ITOglass substrates and the reference patterns of fcc Au (JCPDS 04-0784) and fCC Pt (JCPDS 04-0802). The peaks corresponding to the ITOglass substrate are marked with asterisks $(*)$.
GIXRD patterns of the as-prepared Pt NPs, Au NPs and Au-Pt alloy NPs are shown in Fig. 2. Except for the diffraction features due to the ITO-glass substrates, all the other diffraction peaks for Pt NPs and for Au NPs can be assigned to the fcc phases of metallic Pt (JCPDS 04-0802) and of metallic Au (JCPDS 04-0784), respectively. For the Au-Pt alloy NPs, the more prominent (111) peak at $38.92^{\circ}$ is located in between the $\mathrm{Au}(111)$ feature at $38.19^{\circ}$ and the $\operatorname{Pt}(111)$ feature at $39.81^{\circ}$, which is consistent with the alloy formation. The corresponding interplanar spacing for the (111) reflection of the Au-Pt alloy NPs can be calculated to be $2.312 \AA$ according to Bragg's law. The HRTEM image of a typical Au-Pt alloy NP (shown in Fig. S2, ESI $\dagger$ ) indicates that the NP is single-crystalline, with a (111) interplanar spacing of $2.32 \AA$, consistent with our GIXRD result.

The NP-modified ITO-glass electrodes need to be activated by positive potential under either potentiostatic or potentiodynamic conditions. We have activated the electrodes (potentiodynamically) by performing cyclic voltammetric scans of Pt NPs, $\mathrm{Au}$ NPs, and Au-Pt alloy NPs on ITO-glass electrodes in a solution of $0.5 \mathrm{M} \mathrm{KOH}$ and $0.5 \mathrm{M}$ methanol (Fig. 3). For Pt NPs on the ITO-glass electrode in the methanol-free electrolyte, oxygen evolution occurs at $c a$. $0.6 \mathrm{~V}$, and the reduction peak at $c a$. $-0.4 \mathrm{~V}$ in the backward scan is due to oxygen reduction reaction on the surface of the Pt NPs (Fig. 3b). In the presence of methanol (Fig. 3a), the additional sharp, intense oxidation peak at $-0.19 \mathrm{~V}$ is attributed to methanol oxidation. The methanol oxidation current is found to be small for the first scan. Upon subsequent scans, the methanol oxidation potential is shifted to $-0.22 \mathrm{~V}$ and the current increases till maximum catalytic activity is reached. In a separate experiment, we verify that no methanol electro-oxidation feature can be found for the pristine 
$0.5 \mathrm{M} \mathrm{CH}_{3} \mathrm{OH}+0.5 \mathrm{M} \mathrm{KOH}$

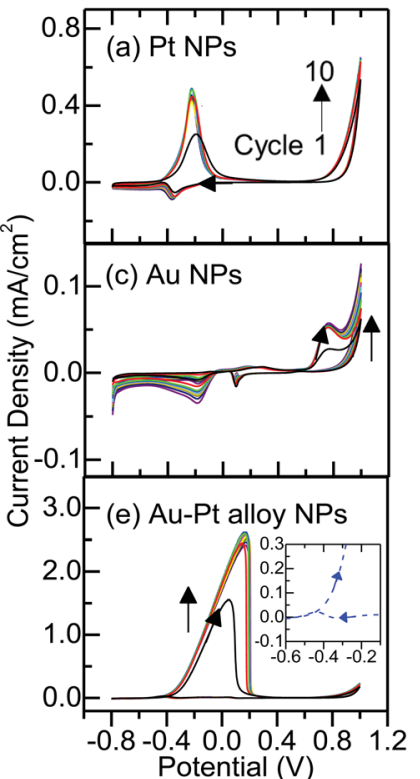

$0.5 \mathrm{M} \mathrm{KOH}$

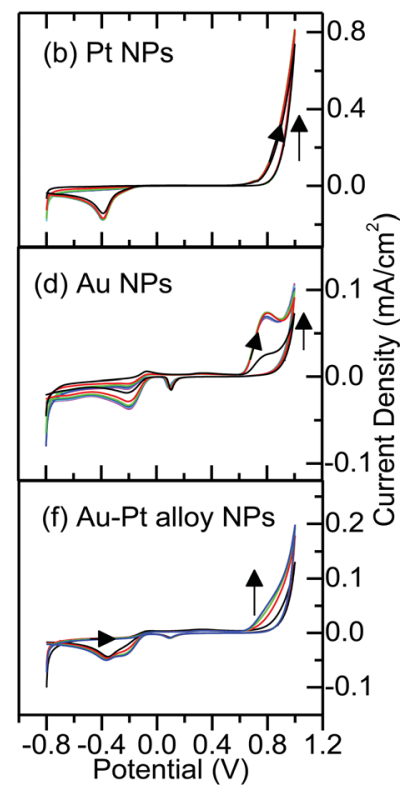

Fig. 3 Cyclic voltammograms initiated in the forward (positive-going) scan direction (marked by arrows) at a scan rate of $10 \mathrm{mV} \mathrm{s}^{-1}$ for (a) and (b) Pt NPs; (c) and (d) Au NPs and (e) and (f) Au-Pt alloy NPs on ITOglass substrates in $0.5 \mathrm{M} \mathrm{KOH}$ solution with and without $0.5 \mathrm{M}$ methanol. Magnified view of the -0.6 to $-0.1 \mathrm{~V}$ region for activated $\mathrm{Au}-\mathrm{Pt}$ alloy NPs in methanol solution is shown in the inset of (e).

ITO-glass substrate, i.e. without any deposited NPs (ESI, Fig. S3†). This clearly illustrates the catalytic activity of the asprepared Pt NPs for electro-oxidation of methanol. For Au NPs (Fig. 3d), the voltammogram for the methanol-free electrolyte shows a small, broad oxidation peak at $0.8 \mathrm{~V}$ and a reduction peak at $c a$. $0.1 \mathrm{~V}$, which are attributed to, respectively, the formation and reduction of surface gold oxide on the NPs. The more intense reduction peak located near $-0.2 \mathrm{~V}$ is due to the oxygen reduction reaction. Upon activation, the intensity of the oxidation peak at $0.8 \mathrm{~V}$ is increased. In the presence of methanol, the voltammograms are found to be similar to that for the absence of methanol, except for the notably weaker intensities. This similarity indicates that the deposited Au NPs even after activation is not catalytic for the methanol electrooxidation. As the most inert noble metal, Au possesses very weak chemisorption properties due to the absence of vacancies in its d-bands. Methanol is therefore not chemisorbed onto the Au NPs, making methanol oxidation unlikely. Tang et al. also reported the lack of any activity of Au NPs (with an average size greater than $50 \mathrm{~nm}$ ) toward methanol oxidation in a $0.5 \mathrm{M}$ methanol/0.5 M KOH solution. ${ }^{37}$ However, Liu et al. found that smaller Au NPs (with an average diameter of $1.7 \mathrm{~nm}$ ) showed a high catalytic activity while larger Au NPs (with a diameter larger than $100 \mathrm{~nm}$ ) did not. ${ }^{38}$ Other earlier studies also reported that Au NPs with diameters of $2 \mathrm{~nm},{ }^{39} 2.5 \mathrm{~nm},{ }^{40}$ and $4 \mathrm{~nm}$ (ref. 41) were catalytically active in methanol electro-oxidation in an alkaline medium. Au NPs with different sizes therefore have different catalytic properties towards methanol electrooxidation. As Au NPs prepared in the present work are found to be $18 \mathrm{~nm}$ in size, the observed lack of activity toward methanol electro-oxidation is therefore consistent with these earlier studies.

In contrast to the Au NPs, no Au oxidation peak is observed in the same solution without methanol for the $\mathrm{Au}-\mathrm{Pt}$ alloy NPs (Fig. 3f), which suggests a different form of $\mathrm{Au}$ in its alloy state. In a solution containing $0.5 \mathrm{M}$ methanol and $0.5 \mathrm{M} \mathrm{KOH}$, a very intense anodic peak at $0.05 \mathrm{~V}$ appears during the forward scan in the first cycle, which can be assigned to the methanol oxidation (Fig. 3e). Upon subsequent scans the methanol oxidation potential is shifted to $0.17 \mathrm{~V}$ and the current increases until the maximum catalytic activity is reached. A smaller methanol oxidation peak at $-0.45 \mathrm{~V}$ (shown in the inset of Fig. 3e) was also observed during the backward scan and this phenomenon is not found for metallic Pt NPs, which illustrates the synergistic effect of Au-Pt alloy NPs. The occurrence of methanol electro-oxidation during the backward scan indicates the resistance of the catalysts to $\mathrm{CO}$ adsorption, ${ }^{42}$ thus validating that the formation of $\mathrm{Au}-\mathrm{Pt}$ alloy could reduce $\mathrm{CO}$ poisoning on the surface of Pt. The intensity of this strong oxidation peak during the forward scan is dependent on the amount of metal NPs present (metal loading) on the ITO-glass substrates. For the supported Pt NPs, quantitative analysis of the Pt content, based on the XPS peak area intensity appropriately normalized by the corresponding relative sensitivity factor, reveals a $6.2 \% \mathrm{Pt}$ surface concentration. The corresponding surface concentration of the metals $(\mathrm{Au}+\mathrm{Pt})$ for the supported $\mathrm{Au}-\mathrm{Pt}$ alloy NPs is 7.6\%. This indicates similar metal loading for the Pt NPs and Au-Pt alloy NPs on the surface of the ITO-glass substrate. Since the maximum current density of methanol electro-oxidation from the Au-Pt alloy NPs $\left(2.63 \mathrm{~mA} \mathrm{~cm}^{-2}\right)$ is over five times that from Pt NPs $\left(0.47 \mathrm{~mA} \mathrm{~cm}^{-2}\right)$, despite their similar average sizes, this therefore shows the superior methanol oxidation capacity of $\mathrm{Au}-\mathrm{Pt}$ alloy NPs $\left(\mathrm{Au}_{72} \mathrm{Pt}_{28}\right)$ compared to Pt NPs. This is an important result because achieving a higher activity at a lower Pt composition is of particular interest in fuel cell research due to the reduction in the cost of fuel cell catalysts. Tang et al. also investigated the electro-catalytic behavior of methanol in alkaline electrolytes for a series of $\mathrm{Au}-$ Pt alloy NPs with different compositions (prepared by electrodeposition onto fluorinated tin oxide substrates). ${ }^{37}$ No information about metal loading is, however, provided to allow proper comparison of their catalytic behavior. Mott et al. reported that $\mathrm{Au}-\mathrm{Pt}$ alloy NPs with a substantial $\mathrm{Au}$ composition (65-85\%) have similar mass activities to metallic Pt NPs for methanol electro-oxidation in the alkaline electrolyte, ${ }^{\mathbf{4 3} 44}$ in contrast to the result in the present work. This difference could be due to post-annealing (at 400-600 ${ }^{\circ} \mathrm{C}$ ) employed after their NP preparation, which is generally expected to have a significant effect on the core and the surface crystallinity of the nanocrystals, and thus their catalytic behavior.

To investigate the general catalytic properties of a bimetallic $\mathrm{Au}-\mathrm{Pt}$ system, we also prepared, in separate experiments, bimetallic NPs by sequential electrodeposition, i.e., Au NPs were first electrodeposited at $-0.3 \mathrm{~V}$ for $1 \mathrm{~s}$ in $1 \mathrm{mM} \mathrm{AuCl}_{3}$ and $0.1 \mathrm{M}$ $\mathrm{NaClO}_{4}$ solutions (step A), which was then followed by deposition of $\mathrm{Pt}$ at $-0.3 \mathrm{~V}$ for $1 \mathrm{~s}$ in a $1 \mathrm{mM} \mathrm{PtCl}_{4}$ and $0.1 \mathrm{M} \mathrm{NaClO}_{4}$ solution (step B). The as-prepared sample, denoted as Pt/Au 

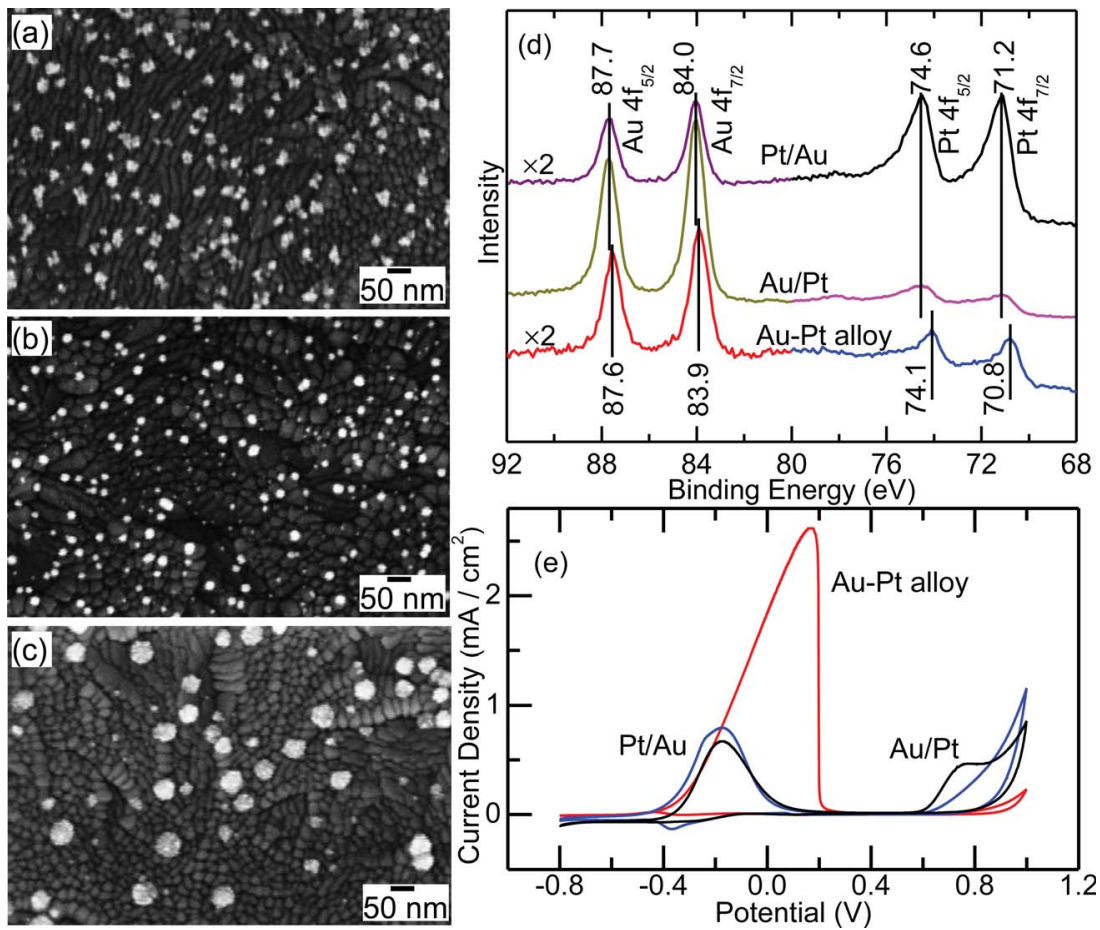

Fig. 4 SEM images of (a) Pt/Au NPs, (b) Au/Pt NPs, and (c) Au-Pt alloy NPs supported on ITO-glass substrates, and (d) their corresponding XPS spectra of the $\mathrm{Au} 4 \mathrm{f}$ and $\mathrm{Pt} 4 \mathrm{f}$ regions and (e) cyclic voltammograms in a solution of $0.5 \mathrm{M}$ methanol and $0.5 \mathrm{M} \mathrm{KOH}$. The scan directions are marked by arrows.

NPs, corresponds to distorted NPs (20 nm in size) uniformly distributed on the ITO-glass substrate (Fig. 4a). Alternatively, we obtained Pt NPs first (step B) followed by deposition of Au (step A). Labelled as Au/Pt NPs, this sample corresponds to spherical NPs with average sizes of $4 \mathrm{~nm}$ and $15 \mathrm{~nm}$ in the size distribution (Fig. 4b). Both the respective XPS spectra (Fig. 4d) for Pt/ $\mathrm{Au}$ NPs and $\mathrm{Au} / \mathrm{Pt}$ NPs show a Pt $4 \mathrm{f}_{7 / 2}\left(4 \mathrm{f}_{5 / 2}\right)$ feature at $71.2 \mathrm{eV}$ (74.6 eV) and a Au $4 \mathrm{f}_{7 / 2}\left(4 \mathrm{f}_{5 / 2}\right)$ feature at $84.0 \mathrm{eV}(87.7 \mathrm{eV})$, corresponding to metallic $\mathrm{Pt}$ and $\mathrm{Au}$, respectively. The absence of any binding energy shift, in contrast to those found for the $\mathrm{Au}-$ Pt alloy NPs with Pt $4 \mathrm{f}_{7 / 2}\left(4 \mathrm{f}_{5 / 2}\right)$ at $70.8 \mathrm{eV}(74.1 \mathrm{eV})$ and $\mathrm{Au} 4 \mathrm{f}_{7 / 2}$ $\left(4 \mathrm{f}_{5 / 2}\right)$ at $83.9 \mathrm{eV}(87.6 \mathrm{eV})$ (Fig. 1i), therefore indicates that alloying does not occur for the two sequential electrodepositions. GIXRD patterns of Pt/Au NPs and Au/Pt NPs also show two distinct sets of diffraction patterns corresponding to Au and Pt, which confirms the bimetallic nature and the absence of alloy formation (ESI, Fig. S4 $\dagger$ ). The electro-oxidation of methanol for $\mathrm{Pt} / \mathrm{Au}$ NPs and Au/Pt NPs are also studied and compared with the Au-Pt alloy NPs (and shown in Fig. 4e). For Pt/Au NPs, the cyclic voltammogram shows a methanol electro-oxidation peak at $-0.18 \mathrm{~V}$ with a current density of $0.79 \mathrm{~mA} \mathrm{~cm}^{-2}$. The absence of an $\mathrm{Au}$ oxidation peak confirms that the subsequent $\mathrm{Pt}$ deposition occurred on top of the individual Au NPs, i.e. the formation of Au-core Pt-shell NPs. Yang et al. reported a much better electro-catalytic activity for $\mathrm{Au}-\mathrm{Pt}$ core-shell NPs than Pt NPs in methanol electro-oxidation reaction. ${ }^{45}$ Their observation is consistent with our results for Pt/Au NPs (i.e. with an Au core and a Pt shell), which also show a higher electro-catalytic activity $\left(0.79 \mathrm{~mA} \mathrm{~cm} \mathrm{~cm}^{-2}\right)$ than the Pt NPs. For Au/Pt NPs, a methanol oxidation peak at $-0.18 \mathrm{~V}$ with a current density of $0.66 \mathrm{~mA} \mathrm{~cm}^{-2}$ and an $\mathrm{Au}$ oxidation peak at $0.7 \mathrm{~V}$ are observed. This indicates that the subsequent deposition of $\mathrm{Au}$ did not completely cover the Pt core. Both bimetallic Pt/Au and $\mathrm{Au} / \mathrm{Pt}$ systems exhibit much lower current densities than the Au-Pt alloy NPs, indicating lower electro-catalytic activities than the $\mathrm{Au}-\mathrm{Pt}$ alloy NPs. The corresponding surface concentrations of the metals $(\mathrm{Au}+\mathrm{Pt})$ for the bimetallic $\mathrm{Pt} / \mathrm{Au}$ and $\mathrm{Au} / \mathrm{Pt}$ systems estimated from their corresponding XPS intensities are $11.7 \%$ and $25.6 \%$, respectively, which are larger than those for the supported $\mathrm{Au}-\mathrm{Pt}$ alloy NPs (7.6\%). The activity of Au-Pt alloy NPs toward methanol electro-oxidation should therefore be higher, even given due consideration to the metal loading effect.

We have also measured the UV-Visible spectra of the Au-Pt alloy NPs, Pt/Au NPs, and Au/Pt NPs, along with those for Pt NPs and Au NPs, all on ITO substrates (ESI, Fig. S5a $\dagger$ ). Other than the spectrum for Au NPs on the ITO substrate with an additional weak broad peak at $549 \mathrm{~nm}$ (due to the Au surface plasmon), the spectra for all the NPs appear to be very similar to one another and to the blank ITO substrate.

Due to the formation of the Au-Pt alloy, the d-band center of $\mathrm{Pt}$ is modified and the resulting changes in the electronic structures could cause the observed high catalytic activity for electro-oxidation of methanol. As Au has been shown to work as a catalyst for $\mathrm{CO}$ oxidation, ${ }^{\mathbf{8}, 9}$ the presence of the $\mathrm{Au}$ component reduces the buildup of $\mathrm{CO}$ and surface oxides on $\mathrm{Pt}$, therefore diminishing the effect of catalyst poisoning on the Au-Pt surface. This synergistic effect is not present on the surface of just Pt NPs but is clearly operative for Au-Pt alloy NPs, which 


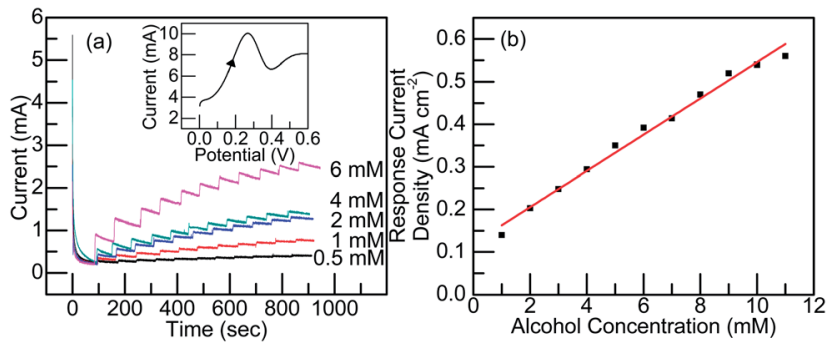

Fig. 5 (a) Typical amperometric response of the Au-Pt alloy NPmodified ITO-glass electrode to successive additions of a $100 \mu \mathrm{L}$ aliquot of aqueous ethanol solution with preselected concentration in an actively stirred electrolyte solution $(20 \mathrm{~mL} 0.5 \mathrm{M} \mathrm{KOH})$. Five ethanol concentrations $(0.5,1.0,2.0,4.0$ and $6.0 \mathrm{mM})$ are used. The current is measured at an applied potential of $0.25 \mathrm{~V}$. The inset shows a linear sweep voltammetric scan of the Au-Pt alloy NP-modified ITO-glass electrode in a solution of $6 \mathrm{mM}$ ethanol and $0.5 \mathrm{M} \mathrm{KOH}$. The scan direction is marked by the arrow. (b) The corresponding response current density as a function of ethanol concentration. The Au-Pt alloy NPs are prepared by electrodeposition at $-0.3 \mathrm{~V}$ for $1 \mathrm{~s}$ in a solution of $1 \mathrm{mM} \mathrm{PtCl}_{4}, 1 \mathrm{mM} \mathrm{AuCl}_{3}$ and $0.1 \mathrm{M} \mathrm{NaClO}_{4}$ on an ITO-glass substrate.

exhibit a very high catalytic activity towards electro-oxidation of methanol.

The aforementioned studies on methanol can be extended to other alcohols. Xie et al. have studied electro-oxidation of various alcohols on Pt electrodes and found that ethanol could be more easily electro-oxidized than methanol. ${ }^{46}$ Indeed, ethanol electro-oxidation is important to such promising applications as direct ethanol fuel cells ${ }^{47}$ and electrochemical sensing. For the ethanol electro-oxidation on Au-Pt alloy NPs, our results (shown in Fig. S6, ESI $\dagger$ ) indicate that a higher activity can also be obtained for Au-Pt alloy NPs than Au NPs, Pt NPs, and $\mathrm{Au}-\mathrm{Pt}$ bimetallic NPs prepared by sequential electrodeposition.

To further demonstrate the superior catalytic properties of these Au-Pt alloy NPs, we characterize the efficacy of these $\mathrm{Au}-\mathrm{Pt}$ alloy NPs as the catalyst material in an alcohol sensor for monitoring ethanol concentration in a solution. The inset in Fig. 5a shows a linear sweep voltammetric curve obtained for $\mathrm{Au}-\mathrm{Pt}$ alloy NPs in a solution of $6 \mathrm{mM}$ ethanol and $0.5 \mathrm{M} \mathrm{KOH}$. The intense oxidation peak that appeared at $0.25 \mathrm{~V}$ corresponds to ethanol oxidation and can therefore be used as a measure of the catalytic activity of Au-Pt alloy NPs to ethanol electrooxidation. In particular, the oxidation current obtained at $0.25 \mathrm{~V}$ can be used for determination of the ethanol concentration. The sensor sensitivity is evaluated by performing amperometric experiments at $0.25 \mathrm{~V}$ using a Au-Pt alloy NP-modified ITO-glass electrode. The Au-Pt alloy NPs are electrodeposited at $-0.3 \mathrm{~V}$ for $1 \mathrm{~s}$ on the ITO-glass substrate. Eleven replicate injections $(100 \mu \mathrm{L}$ each) of a pre-selected concentration of aqueous ethanol solution are administered to the $0.5 \mathrm{M} \mathrm{KOH}$ supporting electrolyte $(20 \mathrm{~mL})$ sequentially. Five ethanol concentrations of $0.5,1.0,2.0,4.0$ and $6.0 \mathrm{mM}$ are used. The successive addition of a $100 \mu \mathrm{L}$ ethanol aliquot induces a small rise in the oxidation current, and the resulting current-time profiles are plotted in Fig. 5a. When the ethanol concentration is increased, a higher jump in the response current is observed. A clear increase in the response current is found even with the addition of alcohol with a concentration as small as $0.5 \mathrm{mM}$. For successive addition of alcohol with concentrations of $0.5,1$ and $2 \mathrm{mM}$ to the supporting electrolyte, a steady-state response current can be reached after just $2 \mathrm{~s}$, which indicates an excellent electrocatalytic response time. For successive addition of $4 \mathrm{mM}$ and 6 $\mathrm{mM}$ ethanol, however, a steady-state current cannot be reached. This is because stirring of the solution used in our experiment is not sufficiently powerful to quickly remove the concentration gradient and to expose uniform concentration of alcohol evenly to the electrode surface. The relationship between the response current density and ethanol concentration (Fig. 5b) is found to be linear for the ethanol concentration range from $1 \mathrm{mM}$ to 11 $\mathrm{mM}$, and the corresponding slope gives a detection sensitivity of $0.043 \mathrm{~mA} \mathrm{~cm}^{-2} \mathrm{mM}^{-1}$. The detection limit is found to be 0.1 $\mathrm{mM}$ by performing the cyclic voltammetric scan in the alcohol solution including $0.5 \mathrm{M} \mathrm{KOH}$, which gives a signal three times

Table 1 Performance comparison of reported alcohol sensors based on metal or metal oxide electrodes

\begin{tabular}{|c|c|c|c|c|c|c|c|}
\hline $\begin{array}{l}\text { Pt electrodeposited with mixed } \mathrm{Co}-\mathrm{Ni} \\
\text { oxide film }\end{array}$ & 0.27 & $1.5-79$ & 0.032 & & $<25$ & 3 & 28 \\
\hline $\begin{array}{l}\text { Au modified by co-electrodeposition of } \\
\text { Pt and } \mathrm{WO}_{3}\end{array}$ & 0.4 & $34-170$ & & 0.28 & 60 & 37 & 20 \\
\hline $\mathrm{RuO}_{2}$-modified Ni & 0.5 & $2.17-21.74$ & & 0.23 & 13 & & 22 \\
\hline Electrodeposited Ni-B thin film & 0.56 & $2.17-13.04$ & & 0.28 & 9 & & 26 \\
\hline CuO-modified $\mathrm{Cu}$ & 0.6 & $1.7-850$ & 0.85 & & & & 24 \\
\hline $\mathrm{Ni} / \mathrm{Pt} / \mathrm{Ti}$ sputtered on $\mathrm{Al}_{2} \mathrm{O}_{3}$ & 0.61 & $0.083-0.50$ & & 3.08 & 27 & & 23 \\
\hline $\begin{array}{l}\text { PtRuNi NPs electrodeposited on glassy } \\
\text { carbon coated with MWNT-ionic liquid } \\
\text { gel }^{a}\end{array}$ & 0.65 & $0.05-38$ & 0.05 & 0.021 & 3 & & 27 \\
\hline
\end{tabular}


the background noise. We also repeat the same sensor evaluation over a period of several months. The Au-Pt alloy NPs electrode retains $95 \%$ of its initial activity even after 3 months, which indicates excellent long-term stability of the sensor at room temperature. For the Au-Pt nanoalloy film deposited on ITO-glass at $-0.3 \mathrm{~V}$ for $5 \mathrm{~s}$, the linear sweep voltammetric scan in a solution of $5 \mathrm{mM}$ ethanol and $0.5 \mathrm{M} \mathrm{KOH}$ shows that the maximum oxidation current density is three times that obtained with a 1 s deposition time (ESI, Fig. S7†). This means increasing the metal loading should produce a better sensor. In comparison with other alcohol sensors based on metal or metal oxide electrodes, the present alcohol sensor therefore exhibits an excellent sensitivity, a shorter response time and a considerably more extended long-term stability (Table 1). Furthermore, this Au-Pt nanoalloy sensor can be operated at a low potential of $0.25 \mathrm{~V}$, which will reduce the interference effect arising from oxidizing other species in the analyte solution.

In summary, we have prepared Pt NPs, Au NPs, and Au-Pt alloy NPs by simple electrodeposition onto ITO-glass substrates and we used them as model catalysts to study the electrooxidation of methanol in a $0.5 \mathrm{M} \mathrm{KOH}$ supporting electrolyte. While Au NPs exhibit no catalytic property for the electrooxidation of methanol, the Au-Pt alloy NPs show a significantly higher catalytic activity than pristine Pt NPs, and bimetallic $\mathrm{Au} /$ $\mathrm{Pt}$ and Pt/Au NP systems. We further demonstrate that these $\mathrm{Au}-\mathrm{Pt}$ alloy NPs can be used as a high-performance alcohol sensor for analyzing alcohol concentration in a solution. This nanoalloy sensor shows excellent linearity in the alcohol concentration range of 1-11 $\mathrm{mM}$, a low detection limit of 0.1 $\mathrm{mM}$, and a good detection sensitivity of $0.043 \mathrm{~mA} \mathrm{~cm}^{-2} \mathrm{mM}^{-1}$. This sensor can be operated at a low potential of $0.25 \mathrm{~V}$, which is desirable for reducing the interference effect arising from other oxidizing species in the analyte solution. The present sensor also has a very fast response time of $2 \mathrm{~s}$ and an extremely long lifetime of up to 3 months at room temperature. Improved control of the size and composition of the $\mathrm{Au}-\mathrm{Pt}$ alloy NPs are necessary to further optimize the sensor performance.

\section{Acknowledgements}

This work was supported by the Natural Sciences and Engineering Research Council of Canada.

\section{References}

1 T. Iwasita, Methanol and CO electrooxidation, Handbook of Fuel Cells, ed. W. Vielstich et al., Wiley, Chichester, UK, 2003, vol. 2, p. 603.

2 J. Müller, G. Frank, K. Colbow and D. Wilkinson, Transport/ Kinetic Limitations and Efficiency Losses, Handbook of Fuel Cells, ed. W. Vielstich et al., Wiley, Chichester, UK, 2003, vol. 4 , p. 847.

3 S. Wasmus and A. Küver, Methanol Oxidation and Direct Methanol Fuel Cells: a Selective Review, J. Electroanal. Chem., 1999, 461, 14-31.

4 Electrocatalysis, Frontiers in Electrochemistry, ed. J. Lipkowski and P. N. Ross, Jr, Wiley-VCH, New York, 1998.
5 E. Herrero, W. Chrzanowski and A. Wieckowski, Dual Path Mechanism in Methanol Electrooxidation on a Platinum Electrode, J. Phys. Chem., 1995, 99, 10423-10424.

6 A. Hamnett, Mechanism and Electrocatalysis in the Direct Methanol Fuel Cell, Catal. Today, 1997, 38, 445-457.

7 E. Antolini, Formation of Carbon-supported PtM Alloys for Low Temperature Fuel Cells: a Review, Mater. Chem. Phys., 2003, 78, 563-573.

8 M. Haruta, When Gold Is Not Noble: Catalysis by Nanoparticles, Chem. Rec., 2003, 3, 75-87.

9 M. Haruta, Size- and Support-dependency in the Catalysis of Gold, Catal. Today, 1997, 36, 153-166.

10 W. C. Ye, H. H. Kou, Q. Z. Liu, J. F. Yan, F. Zhou and C. M. Wang, Electrochemical Deposition of Au-Pt Alloy Particles with Cauliflower-like Microstructures for Electrocatalytic Methanol Oxidation, Int. J. Hydrogen Energy, 2012, 37, 4088-4097.

11 F. Terzi, C. Zanardi, S. Daolio, M. Fabrizio and R. Seeber, AuPt Nanoparticle Systems in Methanol and Carbon Monoxide Electroxidation, Electrochim. Acta, 2011, 56, 3673-3678.

12 M. Khalid, N. Wasio, T. Chase and K. Bandyopadhyay, In Situ Generation of Two-Dimensional Au-Pt Core-Shell Nanoparticle Assemblies, Nanoscale Res. Lett., 2010, 5, 6167.

13 X. Y. Lang, H. Guo, L. Y. Chen, A. Kudo, J. S. Yu, W. Zhang, A. Inoue and M. W. Chen, Novel Nanoporous $\mathrm{Au}-\mathrm{Pd}$ Alloy with High Catalytic Activity and Excellent Electrochemical Stability, J. Phys. Chem. C, 2010, 114, 2600-2603.

14 R. Imbeault, D. Reyter, S. Garbarino, L. Roué and D. Guay, Metastable $\mathrm{Au}_{x} \mathrm{Rh}_{100-x}$ Thin Films Prepared by Pulsed Laser Deposition for the Electrooxidation of Methanol, J. Phys. Chem. C, 2012, 116, 5262-5269.

15 X. F. Xing, D. Q. Han, Y. F. Wu, Y. Guan, N. Bao and X. H. Xu, Fabrication and Electrochemical Property of Hierarchically Porous Au-Cu Films, Mater. Lett., 2012, 71, 108-110.

16 A. D. Modestov, M. R. Tarasevich, A. Y. Leykin and V. Y. Filimonov, MEA for Alkaline Direct Ethanol Fuel Cell with Alkali Doped PBI Membrane and Non-platinum Electrodes, J. Power Sources, 2009, 188, 502-506.

17 N. Fujiwara, Z. Siroma, S. Yamazaki, T. Ioroi, H. Senoh and K. Yasuda, Direct Ethanol Fuel Cells Using an Anion Exchange Membrane, J. Power Sources, 2008, 185, 621-626.

18 J. R. Varcoe and R. C. T. Slade, Prospects for Alkaline AnionExchange Membranes in Low Temperature Fuel Cells, Fuel Cells, 2005, 5, 187-200.

19 A. R. Vijayakumar, E. Csöregi, A. Heller and L. Gorton, Alcohol Biosensors Based on Coupled Oxidase-peroxidase Systems, Anal. Chim. Acta, 1996, 327, 223-234.

20 M. Boujtita, J. P. Hart and R. Pittson, Development of a Disposable Ethanol Biosensor Based on a Chemically Modified Screen-printed Electrode Coated with Alcohol Oxidase for the Analysis of Beer, Biosens. Bioelectron., 2000, 15, 257-263.

21 M. J. L. Castanon, A. J. M. Ordieres and P. T. Blanco, Amperometric Detection of Ethanol with $\operatorname{Poly}(o-$ phenylenediamine)-modified Enzyme Electrodes, Biosens. Bioelectron., 1997, 12, 511-520. 
22 J. Katrlík, J. Švorc, M. Stredanský and S. Miertuš, Composite Alcohol Biosensors Based on Solid Binding Matrix, Biosens. Bioelectron., 1998, 13, 181-191.

23 Y. Chen, K. Y. Chen and A. C. C. Tseung, An Electrochemical Alcohol Sensor Based on a Co-electrodeposited $\mathrm{Pt} \mid \mathrm{WO}_{3}$ Electrode, J. Electroanal. Chem., 1999, 471, 151-155.

24 L. Ciaccheri, E. E. Samano-Baca, M. T. Russo, H. Ottevaere, H. Thienpont and A. G. Mignani, Diffuse-light absorption spectroscopy for beer classification and prediction of alcoholic content, Optical Sensing and Detection II, ed. F. Berghmans, A. G. Mignani and P. De Moor, Proc. of SPIE, 2012, vol. 8439, p. 84392E.

25 Y. C. Weng and T. C. Chou, Ethanol Sensors by Using $\mathrm{RuO}_{2}$ modified Ni Electrode, Sens. Actuators, B, 2002, 85, 246-255.

26 Y. C. Weng, J. F. Rick and T. C. Chou, A Sputtered Thin Film of Nanostructured $\mathrm{Ni} / \mathrm{Pt} / \mathrm{Ti}$ on $\mathrm{Al}_{2} \mathrm{O}_{3}$ Substrate for Ethanol Sensing, Biosens. Bioelectron., 2004, 20, 41-51.

27 T. R. L. C. Paixão and M. Bertotti, Development of a Breath Alcohol Sensor Using a Copper Electrode in an Alkaline Medium, J. Electroanal. Chem., 2004, 571, 101-109.

28 J. J. Huang, W. S. Hwang, Y. C. Weng and T. C. Chou, Determination of Alcohols Using a Ni-Pt Alloy Amperometric Sensor, Thin Solid Films, 2008, 516, 5210-5216.

29 Y. C. Weng and T. C. Chou, Electrodeposited Nickel-Boron Thin-Film Ethanol Sensor Sensors and Displays: Principles, Materials, and Processing, J. Electrochem. Soc., 2006, 153, H127-H132.

30 F. Xiao, F. Q. Zhao, J. J. Zeng and B. Z. Zeng, Novel Alcohol Sensor Based on PtRuNi Ternary Alloy Nanoparticlesmulti-walled Carbon Nanotube-ionic Liquid Composite Coated Electrode, Electrochem. Commun., 2009, 11, 15501553.

31 E. T. Hayes, B. K. Bellingham, H. B. Mark and A. Galal, An Amperometric Aqueous Ethanol Sensor Based on the Electrocatalytic Oxidation at a Cobalt-nickel Oxide Electrode, Electrochim. Acta, 1996, 41, 337-344.

32 J. F. Moulder, W. F. Stickle, P. E. Sobol and K. D. Bomben Handbook of X-ray Photoelectron Spectroscopy, ed. J. Chastain, Perkin-Elmer Corp., 1992, 2nd edn.

33 L. Y. Zhao, N. F. Heinig and K. T. Leung, Formation of Au-Pt alloy Nanoparticles on a Si Substrate by Simple Dip-coating at Room Temperature, Langmuir, 2013, 29, 927-931.

34 Z. Bastl and S. Pick, Angle resolved X-ray Photoelectron Spectroscopy Study of Au deposited on Pt and Re Surfaces, Surf. Sci., 2004, 566-568, 832-836.

35 X. B. Ge, X. L. Yan, R. Y. Wang, F. Tian and Y. Ding, Tailoring the Structure and Property of Pt-Decorated Nanoporous Gold by Thermal Annealing, J. Phys. Chem. C, 2009, 113, 73797384.

36 C. X. Xu, R. Y. Wang, M. W. Chen, Y. Zhang and Y. Ding, Dealloying to Nanoporous Au-Pt Alloys and Their Structure Sensitive Electrocatalytic Properties, Phys. Chem. Chem. Phys., 2010, 12, 239-246.

37 W. Tang, S. Jayaraman, T. F. Jaramillo, G. D. Stucky and E. W. McFarland, Electrocatalytic Activity of Gold Platinum Clusters for Low Temperature Fuel Cell Applications, J. Phys. Chem. C, 2009, 113, 5014-5024.

38 Z. H. Wei and C. J. Liu, Synthesis of Monodisperse Gold Nanoparticles in Ionic Liquid by Applying Room Temperature Plasma, Mater. Lett., 2011, 65, 353-355.

39 J. Luo, M. M. Maye, N. N. Kariuki, L. Y. Wang, P. Njoki, Y. Lin, M. Schadt, H. R. Naslund and C. J. Zhong, Electrocatalytic Oxidation of Methanol: Carbon-supported Gold-platinum Nanoparticle Catalysts Prepared by Twophase Protocol, Catal. Today, 2005, 99, 291-297.

40 F. Terzi, C. Zanardi, S. Daolio, M. Fabrizio and R. Seeber, AuPt Nanoparticle Systems in Methanol and Carbon Monoxide Electroxidation, Electrochim. Acta, 2011, 56, 3673-3678.

41 J. Hernández, J. Solla-Gullón, E. Herrero, A. Aldaz and J. M. Feliu, Methanol Oxidation on Gold Nanoparticles in Alkaline Media: Unusual Electrocatalytic Activity, Electrochim. Acta, 2006, 52, 1662-1669.

42 M. Yin, Y. J. Huang, L. Liang, J. H. Liao, C. P. Liu and W. Xing, Inhibiting CO Formation by Adjusting Surface Composition in PtAu Alloys for Methanol Electrooxidation, Chem. Commun., 2011, 47, 8172-8174.

43 D. Mott, J. Luo, P. N. Njoki, Y. Lin, L. Y. Wang and C. J. Zhong, Synergistic Activity of Gold-platinum Alloy Nanoparticle Catalysts, Catal. Today, 2007, 122, 378-385.

44 J. Luo, P. N. Njoki, Y. Lin, D. Mott, L. Y. Wang and C. J. Zhong, Characterization of Carbon-supported AuPt Nanoparticles for Electrocatalytic Methanol Oxidation Reaction, Langmuir, 2006, 22, 2892-2898.

45 L. Yang, J. H. Chen, X. X. Zhong, K. Z. Cui, Y. Xu and Y. F. Kuang, Au@Pt Nanoparticles Prepared by One-phase Protocol and Their Electrocatalytic Properties for Methanol Oxidation, Colloids Surf., A, 2007, 295, 21-26.

46 S. W. Xie, S. Chen, Z. Q. Liu and C. W. Xu, Comparison of Alcohol Electrooxidation on $\mathrm{Pt}$ and $\mathrm{Pd}$ Electrodes in Alkaline Medium, Int. J. Electrochem. Sci., 2011, 6, 882-888.

47 D. Y. Wang, J. P. Liu, Z. Y. Wu, J. H. Zhang, Y. Z. Su, Z. L. Liu and C. W. Xu, Electrooxidation of Methanol, Ethanol and 1Propanol on $\mathrm{Pd}$ Electrode in Alkaline Medium, Int. J. Electrochem. Sci., 2009, 4, 1672-1678. 